\title{
Karyotypes of Southeastern Turkish Scorpions Hottentotta saulcyi and Buthacus macrocentrus (Scorpiones: Buthidae)
}

\author{
Halil Koc ${ }^{1} \mathbb{D}$, Ersen Aydin Yagmur² $\mathbb{D}^{\text {, }}$, Frantisek Štáhlavský ${ }^{3}$ \\ 'Sinop University, Faculty of Arts and Science, Department of Biology, Sinop, Turkey \\ ${ }^{2}$ Celal Bayar University, Alaşehir Vocational School, Manisa, Turkey \\ ${ }^{3}$ Charles University in Prague, Faculty of Science, Department of Zoology, Prague, Czech Republic
}

ORCID IDs of the authors: H.K 0000-0003-0429-2824; E.A.Y. 0000-0002-0396-3975; F.S.. 0000-0002-8520-9166

Please cite this article as: Koc H, Yagmur EA, Štáhlavský F. Karyotypes of Southeastern Turkish Scorpions Hottentotta saulcyi and Buthacus macrocentrus (Scorpiones: Buthidae). Eur J Biol 2019; 78(2): 111-116. DOI: 10.26650/EurJBiol.2019.0008

\begin{abstract}
Objective: The species Hottentotta saulcyi is widely distributed from Mardin to Hakkari while the distribution of Buthacus macrocentrus is limited to the south-east of Turkey (only Şanlıurfa). The aim of this study is to analyze the cytogenetic structure of Hottentotta saulcyi and Buthacus macrocentrus.

Materials and Methods: The specimens were collected during the night from Şırnak and Şanlıurfa using a UV lamp. The male Hottentotta saulcyi were collected from Şırnak and male and female Buthacus macrocentrus from Şanlıurfa. Chromosome preparations were made using cells from the male testes and the female ovariuteri of the species studied. Chromosome preparations were made using the classical spreading method.

Results: The diploid chromosome number for Hottentotta saulcyi was $2 n=14$, and $2 n=28$ for Buthacus macrocentrus.

Conclusion: The karyotypes of Hottentotta saulcyi and Buthacus macrocentrus have been presented for the first time. Both analyzed species have holocentric chromosomes that gradually decrease in size. Quadrivalent and hexavalent were observed during the first meiotic division in males of Buthacus macrocentrus.
\end{abstract}

Keywords: Karyotype, Hottentotta saulcyi, Buthacus macrocentrus

\section{INTRODUCTION}

Currently, 213 genera and 2433 scorpion species are classified under 17 families (1). Although scorpions are widely distributed in the tropics and subtropics and all types of terrestrial habitats all over the continents (except Antarctica) (2), our present knowledge of their karyotypes is still scarce. Chromosome data on 155 scorpions belonging to 11 families have thus far been determined. Among them, 91 species of Buthidae have been studied, limited to some geographic regions-especially Brazil and Africa (3). Karyotypes of these scorpions are composed of holocentric chromosomes without a localized centromere region (4).
Cytogenetic studies have been carried out on Leiurus abdullahbayrami Yağmur, Koç\&Kunt, 2009 and Compsobuthus matthiesseni (Birula, 1905) present a karyotype with $2 \mathrm{n}=22$ (5), Androctonus crassicauda (Olivier, 1807) has a karyotype of $2 n=24$ (6), Aegaeobuthus gibbosus (Brullé, 1832) shows $2 \mathrm{n}=28$, Mesobuthus eupeus (C.L. Koch, 1839) has $2 \mathrm{n}=20$ (Buthidae) and Euscorpius aladaglarensis Tropea\&Yağmur, 2016 (7) shows 2 n=88 (Euscorpiidae), which are distributed in Turkey.

The present knowledge of the cytogenetics of Turkish scorpions is scarce and fragmented. The aim of this paper is to report the first chromosomal data of two species (Hottentotta saulcyi and Buthacus macrocentrus) from 
Turkey. The genus Hottentotta Birula, 1908 is widespread throughout Africa, the Middle East and Asia $(8,9)$. This genus comprises almost 51 species (10). H. judaicus (Simon, 1872) (11), H. tamulus (Fabricius, 1798) (12-14) and H. trilineatus (Peters, 1861) (15) have been analyzed in cytogenetic studies up to present day. Hottentotta saulcyi (Simon, 1880) was firstly recorded in Mardin (10) and then reported in Batman, Şırnak, and Hakkâri in Turkey (9). Meanwhile, the genus Buthacus Birula, 1908 is distributed across northern and western Africa, Israel, Palestine, Jordan, Syria, Turkey, the Arabian Peninsula, Iraq, Iran, Afghanistan, and Pakistan. 23 species belonging to Buthacus have thus far been described (1, 10, 16-19). In Turkey, Buthacus macrocentrus (Ehrenberg, 1828) is known only from Şanlıurfa $(10,18,20)$. Cytogenetic analyses have been performed for only one species namely Buthacus stockmanni Kovraik, Lowe\&Stahlavsky, 2016 having $2 n=20(21)$.

\section{MATERIALS AND METHODS}

The scorpions were collected using a UV lamp during the night from Şırnak and Şanlıurfa respectively (Figure 1). The collected specimens were transferred to the laboratory in individual plastic containers. In total, six specimens of Hottentotta saulcyi and seven of Buthacus macrocentrus were analyzed (for detailed information, see "Material examined" below).
The gonads were used from both males and females. The specimens were killed by ventral puncture to the prosomal area. Under a stereomicroscope, the gonads were removed by dissection in the presence of physiological salt solution for invertebrates. The gonads were then kept in a hypotonic solution $(0.075 \mathrm{M} \mathrm{KCl})$ for $20 \mathrm{~min}$. The gonads were fixed in a freshly prepared fixative (3: 1, methanol: acetic acid) for $20 \mathrm{~min}$. A few drops of $60 \%$ acetic acid were then dropped on a slide and then shredded with a tungsten needle. The drop on the slide was placed on the heating plate and spread with tungsten needles (22). The prepared slides were stained with 5\% Giemsa in Sörensen's phosphate buffer. The chromosome preparations were analyzed under a Leica DM 500 microscope with a 100x objective. Images were taken with a Leica camera using Leica Application LAZ software. The measurements were analyzed using software ImageJ 1.47 (23) with the plugin Levan (24). The relative length of the chromosomes was calculated as a percentage of the diploid set and it based on seven mitotic metaphases in Hottentotta saulcyi and on seven postpachytene in Buthacus macrocentrus. The preparations were kept in a slide box and the remains of the specimens were fixed in a solution of $96 \%$ alcohol and stored in a refrigerator at $4{ }^{\circ} \mathrm{C}$ at the Zoological Museum of Sinop University, Turkey (ZMSU).

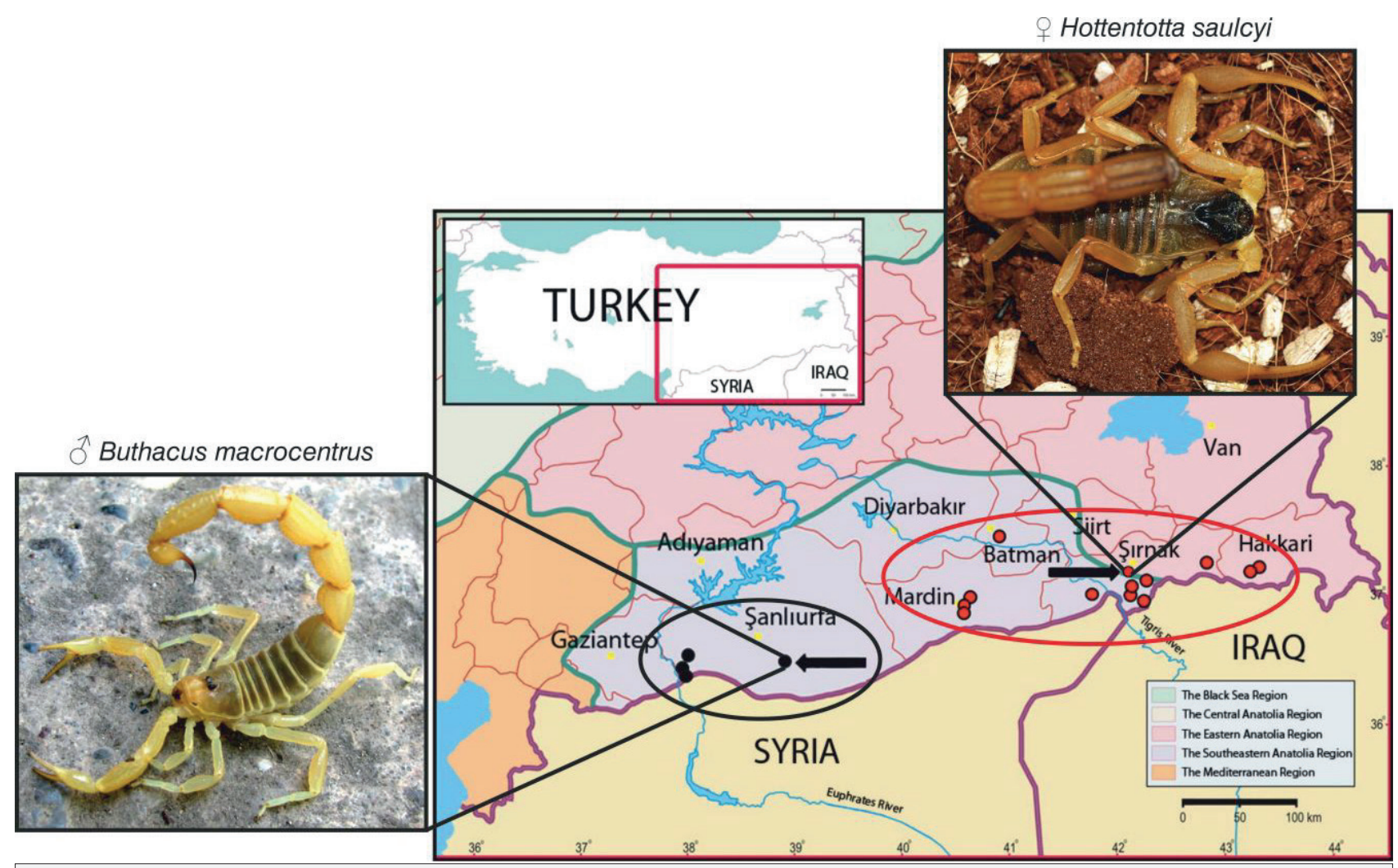

Figure 1. Distribution of Hottentotta saulcyi (red circle) and Buthacus macrocentrus (black circle) in south-eastern Turkey. Arrows show the localities of examined materials. 


\section{RESULTS}

\section{Family : Buthidae C.L. Koch, 1837}

Genus-1 : Hottentotta Birula, 1908

Species-1 : Hottentotta saulcyi (Simon, 1828) (Figures 2 and 3)

Material examined: $2 \hat{\jmath} 3 q$ and $1 \hat{\jmath}$ subadult, Şırnak, $2.5 \mathrm{~km} \mathrm{SW}$ of Şırnak, 37²9'57.3"N; 42²6'32.7"E, 1024 m, 17.07.2014, leg. E. A. Yağmur (Figure 1).
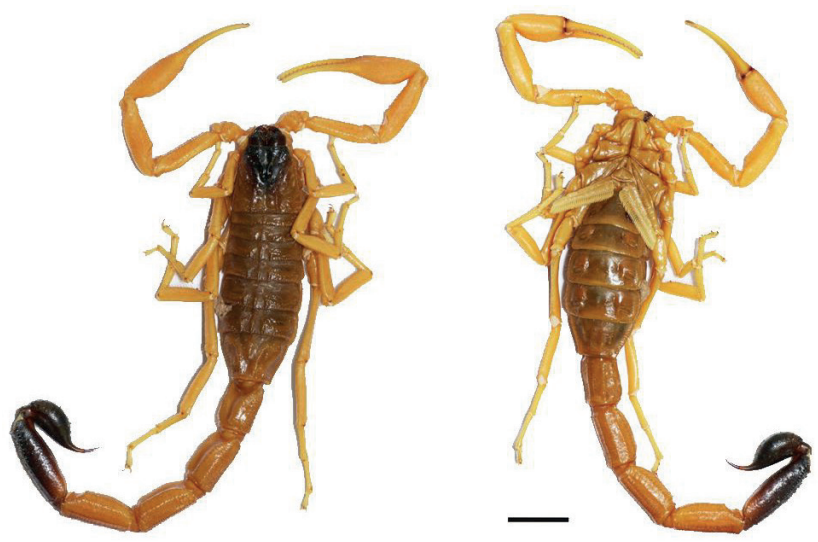

Figure 2. Male Hottentotta saulcyi, dorsal and ventral views. Scale $=1 \mathrm{~cm}$.
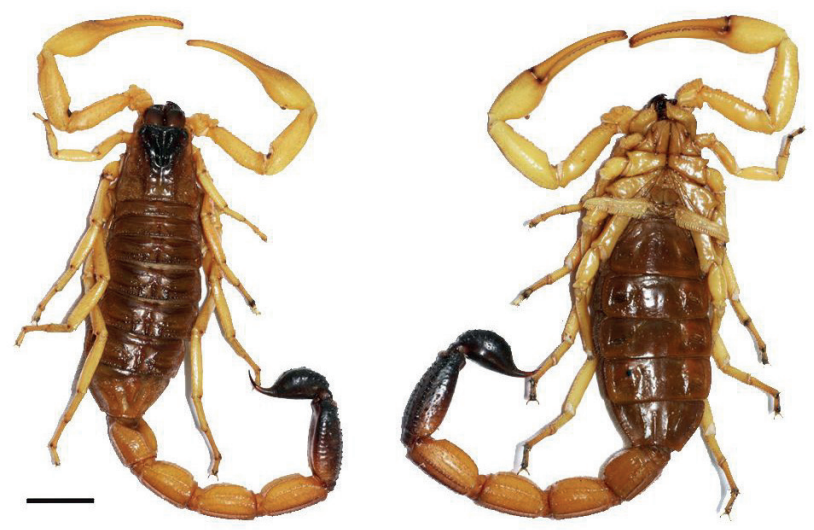

Figure 3. Female Hottentotta saulcyi, dorsal and ventral views. Scale $=1 \mathrm{~cm}$.

\section{Karyotype Investigation}

The chromosome complement of Hottentotta saulcyi consisted of 14 chromosomes (Figure 4). We observed only the mitotic phases for this species. The relative chromosome length gradually decreased from 11.65 to $4.39 \%$ of the diploid set (Figure $4 a$ ).

Genus-2 : Buthacus Birula, 1908

Species-2 : Buthacus macrocentrus (Ehrenberg, 1828) (Figures 5 and 6)

Material examined: $4 \hat{\jmath}$, Şanlıurfa, Birecik District, $2 \mathrm{~km}$ S of Mezra Village, 36 $56^{\prime} 50.1^{\prime \prime} \mathrm{N} ; 38^{\circ} 01^{\prime} 20.3^{\prime \prime} \mathrm{E}, 375 \mathrm{~m}, 08.07 .2013$, leg. E. A. Yağmur. 3 , Şanlıurfa, Birecik District, 2 km S of Mezra Village, $36^{\circ} 57^{\prime} 35^{\prime \prime} \mathrm{N}$; 3800'43"E, 387 m, 27.07.2014, leg. E. A. Yağmur (Figure 1).
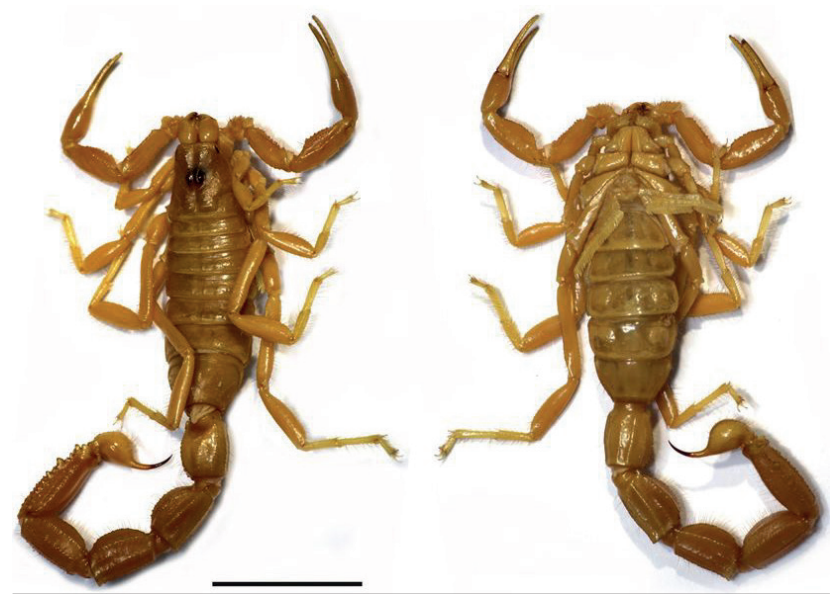

Figure 5. Male Buthacus macrocentrus, dorsal and ventral views. Scale $=1 \mathrm{~cm}$.

\section{Karyotype Investigation}

The number of diploid chromosomes in all male and female Buthacus macrocentrus specimens examined was 28 (Figure 7a). The relative chromosome length of the first chromosome $(6.31 \%)$ was slightly larger than the remaining chromosomes which

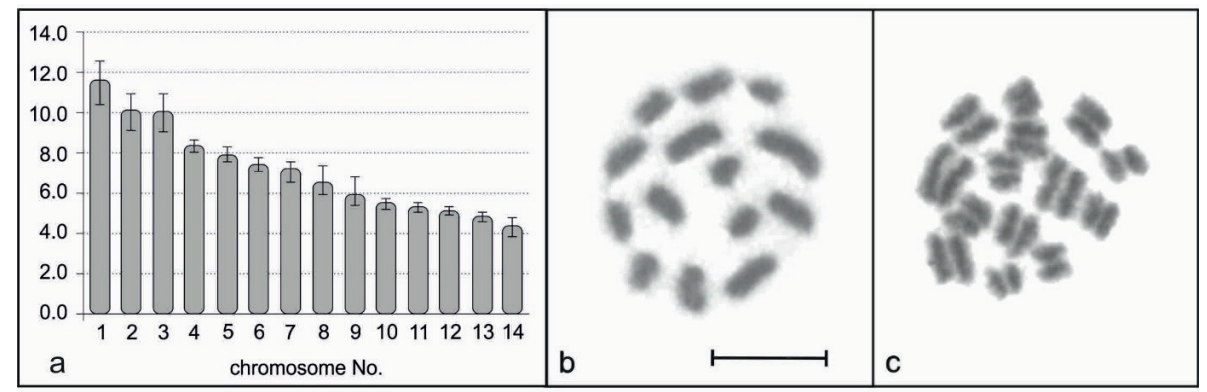

Figure 4. Ideogram and chromosomes of male Hottentotta saulcyi, $2 n=14$. a. ideogram based on mitotic metaphases ( $y$ axis - \% of the diploid chromosome length, lines indicate min.-max. values); b. mitotic metaphase; c. early mitotic anaphase. Scale=10 $\mu$ m. 


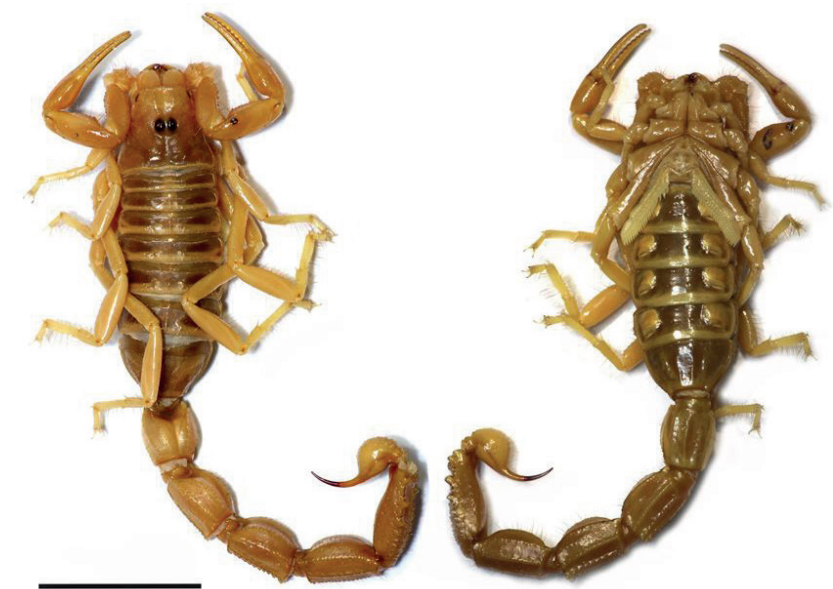

Figure 6. Female Buthacus macrocentrus, dorsal and ventral views. Scale $=1 \mathrm{~cm}$.

gradually decreased from 5.14 to $1.95 \%$ of the diploid set (Figure 7a). Achiasmatic bivalents were detected in males during the first meiotic division. In the female, mitotic metaphases were obtained (Figure 7b). A distinct quadrivalent or hexavalent association of chromosomes were found in all individuals and observed in four males during meiosis (Figures $7 \mathrm{c}$ and $\mathrm{d}$ ). The size of the detected multivalent chromosomes gradually reduced. The chromosomes forming quadrivalent or hexavalent were different in size (Figure 7a). During the first meiosis division phase (anaphase, pachytene, postpachytene, metaphase-I), no indication of crossing-over was observed. In the polar view of metaphase I (Figures $7 \mathrm{~b}$ and $\mathrm{c}$ ), the majority of these bivalents presented parallel-arranged homologous chromosomes. In pachytene (Figure 7e), bivalents were all strip-shaped.

\section{DISCUSSION}

The present study provides the first cytogenetic analysis of the Hottentotta saulcyi and Buthacus macrocentrus, species of the Buthidae family. The karyotypes of these species consist of 14 and 28 chromosomes (Table 1). 91 species of Buthidae have been cytogenetically studied thus far, and which show the lowest chromosome numbers within scorpions. This family has a diploid chromosome number varying from $2 n=5$ [Tityus bahiensis (Perty, 1833)] to $2 n=36$ [Barbaracurus somalicus (Hirst, 1907) and Parabuthus mossambicensis (Peters, 1861)], excluding dubious information (see 3). Buthidae family, as well as the entire order Scorpiones, is characterized by achiasmatic meiosis in males (25). In contrast to other scorpions, the examined species of buthids usually possess a relatively low chromosome number and all of them have holocentric organization (4).

Although there are several faunistic and taxonomic studies on the genus Hottentotta, there is a paucity of cytogenetic studies.

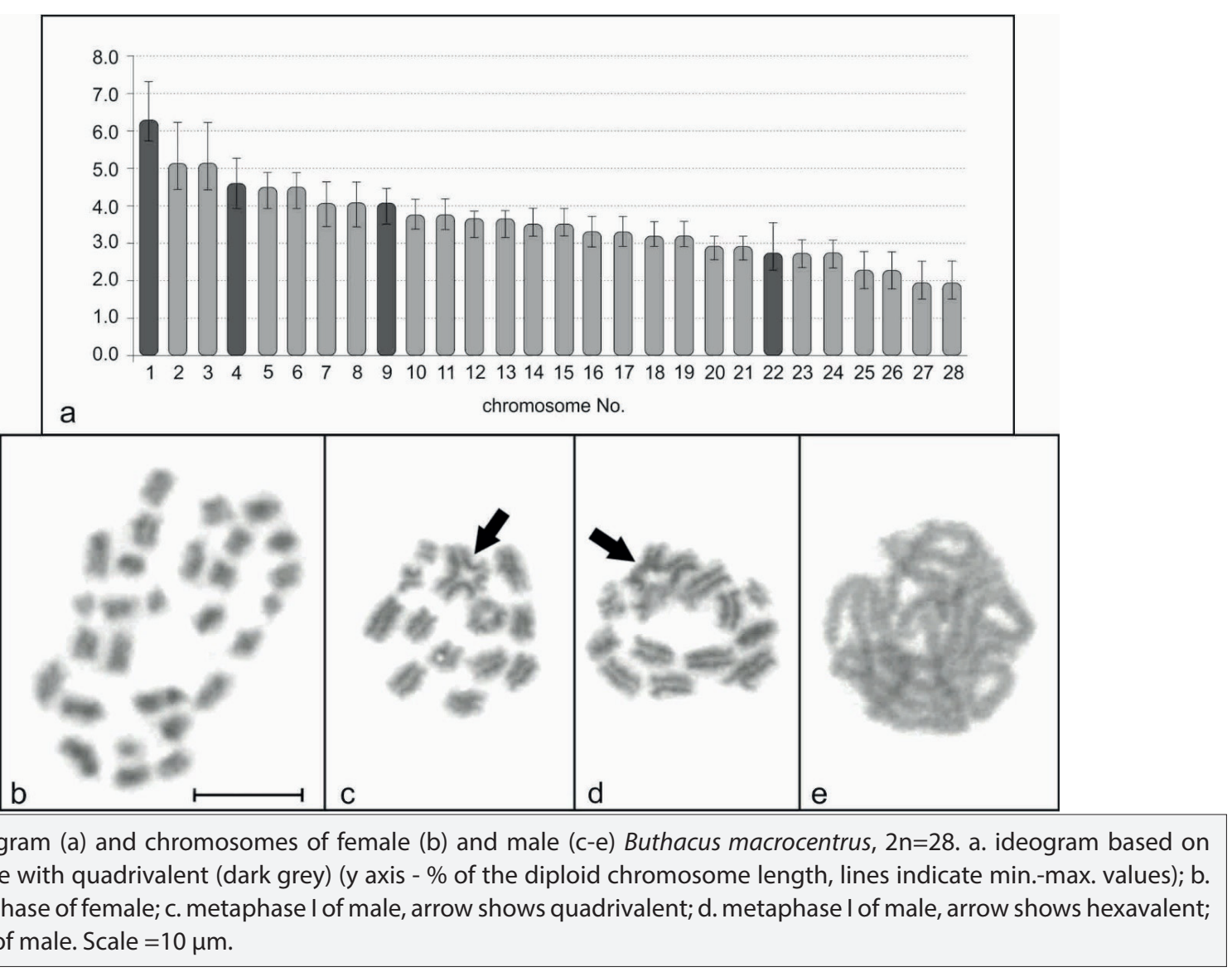


Table 1: Number of diploid chromosomes in eight species of scorpions from Turkey.

\begin{tabular}{lllll}
\hline Taxon & $\mathbf{2 n}$ & Sampling locality & Reference \\
\hline Buthidae & & & & \\
\hline Androctonus crassicauda (Olivier, 1807) & 24 & Turkey: Şanlıurfa Province & (6) \\
\hline Buthacus macrocentrus (Ehrenberg, 1828) & 28 & Turkey: Şanlıurfa Province & the present study \\
\hline Compsobuthus matthiesseni (Birula, 1905) & 22 & Turkey: Gaziantep Province & (5) \\
\hline Hottentotta saulcyi (Simon, 1880) & 14 & Turkey: Şırnak Province & the present study \\
\hline Leiurus abdullahbayrami Yağmur, Koç \& Kunt, 2009 & 22 & Turkey: Gaziantep Province & (5) \\
\hline $\begin{array}{l}\text { Mesobuthus eupeus (C. L. Koch, 1839) } \\
\text { Aegaeobuthus gibbosus (Schenkel, 1947) }\end{array}$ & 20 & Turkey: Niğde Province & (7) \\
\hline Euscorpiidae & 28 & Turkey: Niğde Province & (7) \\
\hline Euscorpius aladaglarensis Tropea \& Yağmur, 2016 & 88 & Turkey: Niğde Province & (7)
\end{tabular}

Chromosomal data are known for only three of the total of 51 currently recognized species of the genus Hottentotta species (10), were included in cytogenetic studies (11-15). Hottentotta tamulus species possesses $2 \mathrm{n}=22,24$ or $20-28$ chromosomes forming a continuous series (12-14). But, Venkatanarasimhiah and Rajasekarasetty (13) stated that the chromosome number of same species have $2 n=23$ stable chromosome number in India. Sharma et al. (12) observed the tetravalent formation which is very common in $\mathrm{H}$. tamulus. The diploid number was given as $2 \mathrm{n}=24$ for Hottentotta trilineatus by Newlands and Martindale (15). Qumsiyeh et al. (11) reported diploid chromosomes as $2 \mathrm{n}=16$ for Hottentotta judaicus specimens from the Palestinian Territories. We obtained diploid chromosomes as $2 \mathrm{n}=14$ for Hottentotta saulcyi. Our results supported that genus Hottentotta displays interspecific karyotype differences with $2 \mathrm{n}$ ranging from 14 (this study) to 24. However, we could not observe multivalent in $H$. saulcyi as previously documented in $\mathrm{H}$. tamulus.

The genus Buthacus was studied cytogenetically for the first time by Kovařík et al. (21). The karyotype of B. stockmanni has $2 n=20$ chromosomes with holocentric and achiasmatic meiotic complement (21). According to cytological observation of $B$. stockmanni, the first pair of chromosomes are distinctively larger ( $13.41 \%$ of the diploid set) than the other chromosomes that gradually decrease from $5.84 \%$ to $2.69 \%$ of the diploid set. The cytogenetic analyses revealed that Buthacus macrocentrus consisted of $2 n=28$. The chromosomes are holocentric and achiasmatic meiotic complement as Kovařík et al. (21). The ideogram show that chromosomes of 1, 4, 9 and 22 are involving the arrangement of quadrivalent chromosome (Fig. a). These findings confirm the results of Shanahan and Hayman (26) who stated that multivalent formations involve during the achiasmate meiosis of buthid. The first chromosome is significantly longer (6.31\%) than the remaining chromosomes that gradually decrease from $5.14 \%$ to $1.95 \%$ of the diploid set.
In our present study, it is interesting to note that the presence of quadrivalents and hexavalents seems to be frequent in $B$. macrocentrus species.

\section{CONCLUSION}

Our analysis of karyotype data provides a first step towards understanding the chromosome numbers and the structure of chromosomes in one of the most important and dangerously venomous members of the family Buthidae. In general, our findings support that buthids have a low chromosome number with holocentric chromosomes. In the present study, the karyotype of two buthids, Hottentotta saulcyi and Buthacus macrocentrus, was identified for the first time as $2 n=14$ and $2 n=28$ respectively. The genus Hottentotta possess interspecific karyotype differences in a continuous series of the chromosomal number with $2 \mathrm{n}$ ranging from 14 to 24 . As far as we know, this is the second karyological analysis of the genus Buthacus, thus our study is a significant contribution to the description of the chromosomal features of Buthacus macrocentrus. Our data highlights that the frequency of the multivalent is very high in this species. The chromosomes were arranged and numbered according to their total length in a gradually decreasing size order and their ideogram was developed (see Fig. 4a and Fig. 7a). Nevertheless, the results show that chromosome numbers are not a useful character in some buthids, and are therefore not effective for taxonomic purposes. Moreover, more detailed analysis of the karyotype of the buthid species is required for comparative cytotaxonomy of the Buthidae.

Peer-review: Externally peer-reviewed.

Author Contributions: Conception/Design of study: H.K.; Data Acquisition: H.K., E.A.Y.; Data Analysis/Interpretation: H.K., F. Š.; Drafting Manuscript: H.K.; Critical Revision of Manuscript: H.K., F. Š., E.A.Y.; Final Approval and Accountability: H.K. 
Conflict of Interest: The authors declare that they have no conflicts of interest.

Financial Disclosure: The project was financially supported by the Sinop University BAP Unit (FEF 1901-13-03).

\section{REFERENCES}

1. Rein JO. The Scorpion Files. Trondheim: Norwegian University of Science and Technology. [Accessed 2019.01.23]. Available from https://www.ntnu.no/ub/scorpion-files 2019.

2. Dunlop JA, Penney D. Fossil Arachnids. Monograph Series Volume 2. Siri Scientific Press, Manchester 2012; 192 pp.

3. Schneider MC, Mattos VF, Cella DM. The scorpion cytogenetic database. Available in www.arthropodacytogenetics.bio.br/ scorpiondatabase 2019.

4. Mattos VF, Cella DM, Carvalho LS, Candido DM, Schneider MC. High chromosome variability and the presence of multivalent associations in buthid scorpions. Chrom Res 2013; 21:121-36.

5. Štáhlavský $\mathrm{F}, \mathrm{Koç} \mathrm{H}$, Yağmur EA. The first record of karyotypes in Leiurus abdullahbayrami and Compsobuthus matthiesseni (Scorpiones: Buthidae) from Turkey. North-West J Zool 2014; 10 (2): 355-8.

6. Sadílek D, Nguyen $P$, Koç H, Kovarik F, Yağmur EA, Štáhlavský $F$. Molecular cytogenetics of Androctonus scorpions: an oasis of calm in the turbulent karyotype evolution of the diverse family Buthidae. Biol J Linn Soc 2015; 115: 69-76.

7. Karataş Ay, Uçak M, Karataş Ah, Eroğlu O. Records of chromosomal data of some scorpions (Arachnida: Scorpiones) from Turkey. Hacettepe J Biol\&Chem 2019; 47(1): 1-6.

8. Kovarík F. A revision of the genus Hottentotta Birula, 1908, with descriptions of four new species (Scorpiones, Buthidae). Euscorpius 2007; 58: 1-109.

9. Yağmur EA, Koç K, Yalçın M. Distribution of Hottentotta saulcyi (Simon 1880) (Scorpiones: Buthidae) in Turkey. Euscorpius 2008; 76: 1- 8.

10. Crucitti P, Vignoli V. Gli scorpioni (Scorpiones) dell'Anatolia sudorientale (Turchia). Boll Mus Reg Sci Nat 2002; 19 (2): 433-80.

11. Qumsiyeh MB, Salman INA, Salsaa' M, Amr ZS. Records of scorpions from the Palestinian Territories, with the first chromosomal data (Arachnida: Scorpiones). Zool Middle East 2013; 59: 70-6.

12. Sharma GP, Parshad R, Joneja MG. Chromosome mechanism in the males of three species of scorpions (Scorpiones-Buthidae). Res Bull Panjab Uni 1959; 10: 197-207.
13. Venkatanarasimhiah CB, Rajasekarasetty MR. Contributions to the cytology of Indian scorpions. Experientia 1964; 21: 154.

14. Gupta AKD, Sarker SK. A study of the meiotic chromosomes of the scorpion Buthus tamulus Fabr. Curr Sci 1965; 2: 54-5.

15. Newlands G, Martindale CB. The buthid scorpion fauna of ZimbabweRhodesia with checklists and keys to the genera and species, distributions and medical importance (Arachnida: Scorpiones). South African Ins Med Res 1980; 67: 51-77.

16. Levy G, Amitai P. Scorpiones, In: Fauna Palaestina, Arachnida I., Israel Acad. Sci. Human., Jerusalem 1980; 130 pp.

17. Fet V, Lowe G. Family Buthidae. pp. 54-286. In: Fet V, Sissom WD, Lowe G, Braunwalder ME. Catalog of the Scorpions of the World (1758-1998). The New York Entomological Society, New York 2000; 690 pp.

18. Kovařík F. Taxonomic position of species of the genus Buthacus Birula, 1908 Described by Ehrenberg and Lourenço, and description of a new species (Scorpiones: Buthidae). Euscorpius 2005; 28: 1-13.

19. Lourenço WR. Further considerations on the genus Buthacus Birula, 1908 (Scorpiones, Buthidae), with a description of one new species and two new subspecies. Bol SEA 2006; 38: 59-70.

20. Yağmur EA, Yalçın M, Çalışır G. Distribution of Androctonus crassicauda (Olivier, 1807) and Buthacus macrocentrus (Ehrenberg, 1828) (Scorpiones: Buthidae) in Turkey. Serket 2008; 11(1): 13-8.

21. Kovařík F, Lowe G, Štáhlavský F. Review of northwestern African Buthacus, with description of Buthacus stockmanni sp. n. from Morocco and western Sahara (Scorpiones, Buthidae). Euscorpius 2016; 236: 1-18.

22. Traut W. Pachytene mapping in the female silkworm, Bombyx mori L. (Lepidoptera). Chromosoma 1976; 58: 275-84.

23. Schneider C.A., Rasband W.S., Eliceiri K.W. NIH Image to ImageJ: 25 years of image analysis. Nat Meth 2012; 9: 671-5.

24. Sakamoto, Y., Zacaro A.A. LEVAN, an ImageJ plugin for morphological cytogenetic analysis of mitotic and meiotic chromosomes. http:// rsbweb.nih.gov/ij/plugins/levan/levan.html 2009.

25. Shanahan C. Cytogenetics of Australian scorpions. I. Interchange polymorphism in the family Buthidae. Genome 1989; 32:882-9.

26. Shanahan C., Hayman, D. Synaptonemal complex formation in male scorpions exhibiting achiasmate meiosis and structural heterozygosity. Genome 1990; 33: 914-26 